\title{
THE PREPARATION OF DEXTRINE-MALTOSE (MALT SUGAR) AND ITS
} USE IN BREWING.

By Wm. Geo. Valentin, F.C.S., Royal College of Chemistry, Sodth Kensington. Abstracted from "Journal of Society of Arts," March 24th, 1876.

THE author describes some improvements made by himself and Mr. Cornelius .O'Sallivan, in the preparation of a sugar for brewers' use.

In order to show the advantage of dextrine-maltose, the author first dwells upon the composition of malt, showing that by a study of the constituents contained in malt before and after infusion, in connection with those contained in the fermented beer, much additional insight into the brewing process may be gained.

The published analysis of malt are, upon the authority of Mr. O'Sullivan, not to be relied upon.

Oudemans states that malt contains 8 per cent. of dextrine, O'Sullivan cannot find any ; again, the amount of sugar is usually set down at from $\cdot 4$ to 1 per cent; 0 'Sullivan finds from 16 to 20 per cent. About half of this is due to the transformation during the malting process of starchy matter, the remainder of the sugar is ready formed in barley, and differs from the one produced by malting.

The starch of barley contains a carbohydrate of the type having a laevo-rotatory action on polarised light. Kühnemann calls this body " Sinistrin," but from its general character, O'Sullivan is inclined to think that it is "Inulin."

The following table gives the detailed composition of two samples of pale malt, every item of which has been estimated directly and not by difference :-

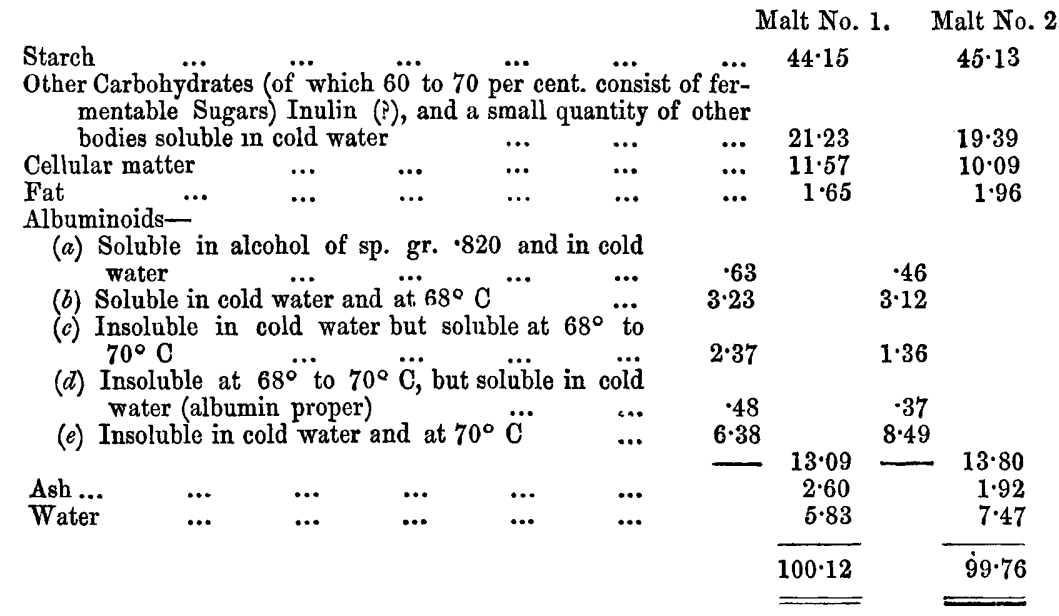

When ground malt is submitted to the mashing process, certain of the albuminiod bodies contained in the malt act upon the starch, and the latter is dissolved.

The wort, therefore, contains the transformation products of the starch, principally dextrine maltose of the other carbohydrates, the soluble albuminoids, the soluble portion of the ash, and a little soluble fat.

Boiling with hops removes a portion of the albuminoids, but the starch products are but slightly altered. 
When the boiled hopped wort is subsequently submitted to the action of yeast, the carbohydrates, other than those derived from starch, yield alcohol first, and the portion which is fermentable (60 to 70 per cent.) disappears almost altogether, and there remains in the beer, when the first stage of the fermentation is over, and when it is fit to go into the casks, the alcohol and a portion of the carbonic acid derived from the carbohydrates other than starch, and also from a portion of the products of the transformation of the starch itself, effected by the ferments. Hence the whole of the dextrine, a considerable portion of maltose, the remainder of the albuminoids, the soluble matter of the hop, and a fe w other constituents are left for after fermentation.

In order to understand the part which the dextrine and maltose play in the after history of the beer, the author examined the constitution of a typical Burton Pale Ale, when the principal fermentation was finished. The sample showed an original gravity of 1063 , and gave when finished and ready to be put into casks a distillate of spirit grains $\cdot 992$, equal to 33.7 degrees of gravity lost. The unboiled wort of this beer, supposing it had been brewed from No. 1 malt and reduced to the above specific gravity, viz. 1063, after allowing for concentration on boiling, would contain in every 100 parts by measure the following solid constituents :-

\begin{tabular}{|c|c|c|c|c|c|}
\hline Maltose $\ldots$ & $\cdots$ & $\cdots$ & $\cdots$ & & $6 \cdot 66$ \\
\hline Dextrine ... & $\ldots$ & ... & ... & & $3 \cdot 44$ \\
\hline Other Carbohydrates, fermentable & $\ldots$ & $\ldots$ & $\ldots$ & $\ldots$ & $3 \cdot 30$ \\
\hline Ditto unfermentable & $\ldots$ & $\ldots$ & $\ldots$ & $\ldots$ & 1.48 \\
\hline $\begin{array}{l}\text { Albuminoids } \\
\text { Ash, Phosphates, Sulphates, } \dddot{\& c .}\end{array}$ & $\cdots$ & $\ldots$ & $\cdots$ & $\cdots$ & $\begin{array}{l}1.45 \\
0.17\end{array}$ \\
\hline & & Total & $\ldots$ & $\ldots$ & \\
\hline
\end{tabular}

After boiling with hop (and correction for loss by evaporation, so as to keep it at the normal original gravity of 1063) it was composed as follows:-

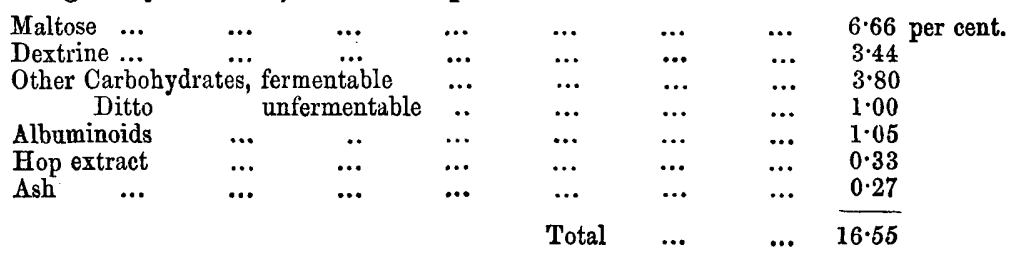

Hence it follows that the fundamental constituents of the hopped wort had undergone but little change, when the principal fermentation with yeast was finished and the ale ready to be put into the cask, the beer contained :-

\begin{tabular}{|c|c|c|c|c|c|c|}
\hline \multirow[b]{2}{*}{ Alcohol } & \multirow[b]{2}{*}{$\ldots$} & \multirow[b]{2}{*}{$\cdots$} & \multicolumn{4}{|c|}{$\begin{array}{l}\text { Alcohol and solida } \\
\text { in } 100 \text { parts. }\end{array}$} \\
\hline & & & $\cdots$ & $\ldots$ & $4 \cdot 48 \mathrm{~s}$ & sp. gr. $\cdot 992$ \\
\hline Maltose & $\cdots$ & $\cdot \cdot$ & & & 1.52 & \\
\hline Dextrine & $\ldots$ & & ... & $\ldots$ & $3 \cdot 44$ & \\
\hline Carbohydrate & s ferment & table & $\ldots$ & $\ldots$ & trace. & \\
\hline Ditto, & unferm & entable & $\ldots$ & $\ldots$ & $1 \cdot 00$ & \\
\hline Albuminoids & $\ldots$ & $\ldots$ & $\ldots$ & & $\cdot 66$ & \\
\hline Hop Extract & & $\cdots$ & $\ldots$ & $\ldots$ & $\cdot 33$ & \\
\hline Non-volatile & Products & of the & ermer & on... & $\cdot 47$ & \\
\hline $\operatorname{Ash} \ldots$ & $\ldots$ & $\cdots$ & $\cdots$ & $\ldots$ & $\cdot 24$ & \\
\hline & & & & & $7 \cdot 66$ & \\
\hline
\end{tabular}

If we examine the malt analyses given above, and suppose that during the mashing process the malt yielded an extract of 74 per cent., we perceive that the starch amounts to little more than 59.6 per cent. ; the maltose and dextrine in the wort to a little more 
than 61 per cent. of the extract, the increase being due to the binding of water. This very closely corresponds to the theoretical percentage of these bodies, obtainable, if starch splits up, according to the equation:-

$$
\underbrace{\mathrm{C}^{18} \mathrm{H}^{30} \mathrm{O}^{15}}_{\text {Starch. }}+\mathrm{OH}^{2}=\underbrace{\mathrm{C}^{12} \mathrm{H}^{2} \mathrm{O}^{11}}_{\text {Maltose. }}+\underbrace{\mathrm{C}^{6} \mathrm{H}^{10} \mathrm{O}^{5}}_{\text {Dextrine. }}
$$

that is, 32.15 per cent. of dextrine and 67.85 of maltose.

If the composition of the boiled wort given above be examined, it will be found that about 64 per cent. is fermentable matter. In all well conducted brewing operations, at the time of racking the beer, if the original gravity be determined, few instances will occur in which the amount of matter fermented is more than 64 per cent. of the original solid matter before fermentation. There may be cases in which this number is exceeded, as in old beers, in which the after-fermentation had taken place, or badly brewed beers, in which proper attention had not been paid to the mashing operation.

It is pretty well understood that if a pale ale, the worts of which had, say a specific gravity of 1063-1064, can be got into the cask when it is reduced by fermentation down to $1020-1021$, things are going on rightly. The meaning of this is not far to seek. The wort would contain in every 100 parts, by measure, 16.5 parts by weight, or thereabouts of solid matter of the composition already referred to. The specific gravity of the finished beer being taken at 1021, the specific gravity of the spirit contained in the finished beer would be 992 , or 8 less than 1000 . The specific gravity of the finished beer, taken at 1021, the specific gravity of the beer without the alcohol would amount to $1029(1021+8)$. This represents $7 \cdot 6$ per 100 of solid matter, or $16 \cdot 5-7 \cdot 6=8 \cdot 9$ of converted matter, and when expressed in percentage numbers $=53 \cdot 9$, say 54 per cent., thus leaving still in the beer, as shown above, about 10 per cent. (on original extract) of fermentable matter. This matter is maltose, and it serves to keep up, by its slow and gradual fermentation, the condition of the beer in cask.

Malt being sweet, and it not being understood to what the sweetness was due, cane sugar, invert sugar, and glucose, or so-called saccharines of various kinds have been proposed as substitutes.

If cane sugar be submitted to the action of yeast, it will be found, if sufficient yeast be added, and the temperature of the mixture be maintained at from $20^{\circ}$ to $30^{\circ} \mathrm{C}$. that the whole of it ferments in four or five days, and yields 51 to 51.5 per cent. of alcohol, together with a certain proportion of succinic acid, glycerine, and other products. The residue left on fermenting a portion of the cane sugar always tastes acid and "thin;" the acid taste is no doubt due to the succinic acid, and the thinness to the peculiar sharp bodiless taste of the sugar.

If one-third of the malt extract in the pale ale mentioned above be replaced by cane sugar, the wort before boiling would then have the following composition :-

\begin{tabular}{lcccc} 
& & \multicolumn{3}{c}{ Per 100 parts by } \\
Cane Sugar & $\ldots$ & $\ldots$ & $\ldots$ & 5.57 \\
Maltose $\ldots$ & $\ldots$ & $\ldots$ & $\ldots$ & 4.53 \\
Dextrine $\ldots$ & $\ldots$ & $\ldots$ & $\ldots$ & 2.14 \\
Other Carbohydrates, fermentable & $\ldots$ & 2.20 \\
Ditto, non-fermentable & $\ldots$ & $\ldots$ & 0.99 \\
Albuminoids & $\ldots$ & $\ldots$ & $\ldots$ & 0.98 \\
Ash $\quad .$. & $\ldots$ & $\ldots$ & $\ldots$ & 0.11 \\
& & & & 16.52
\end{tabular}


After boiling with the hop it would contain-

\begin{tabular}{lcccc} 
& & \multicolumn{3}{c}{ Per 100 parts by } \\
Cane Sugar & $\ldots$ & $\ldots$ & $\ldots$ & 5.57 \\
Maltose $\ldots$ & $\ldots$ & $\ldots$ & $\ldots$ & 4.53 \\
Dextrine $\ldots$ & $\ldots$ & $\ldots$ & $\ldots$ & 2.14 \\
Other Carbohydrates, fermentable & $\ldots$ & 2.53 \\
Ditto, non-fermentable & $\ldots$ & $\ldots$ & 0.66 \\
Albuminoids & $\ldots$ & $\ldots$ & $\ldots$ & 0.70 \\
Hop Extrast & $\ldots$ & $\ldots$ & $\ldots$ & 0.39 \\
Ash $\ldots$ & $\ldots$ & $\ldots$ & $\ldots$ & 0.21 \\
& & & & 16.73
\end{tabular}

The analysis is of a beer in which the same amount of hops was used as in the previous case. The numbers are before fermentation. It contains-

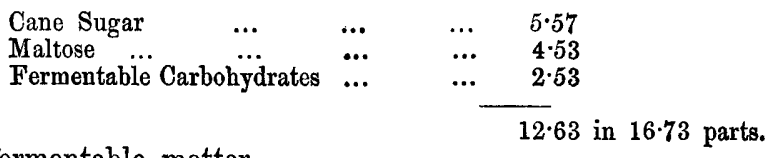

i.e., 75 per cent. of fermentable matter.

Cane sugar can never be used as a substitute for malt in the brewing of keeping beers. Keeping, even for a short time, attenuates them so much, that all body and flavour are gone.

The next substance to be dealt with is the so-called "invert sugar." The analysis of two samples I have before me. They appear as semi-solid, straw-coloured, honeylike substances. No. 1 gave 85 per cent., and No. 2, 86.88 per cent. of solid matter. Hence 85 parts of cane sugar would go as far as 100 parts of No. 1 ; and 86.88 of cane sugar as far as 100 parts of No. 2; but 100 parts of cane sugar yield 105.26 parts of invert sugar.

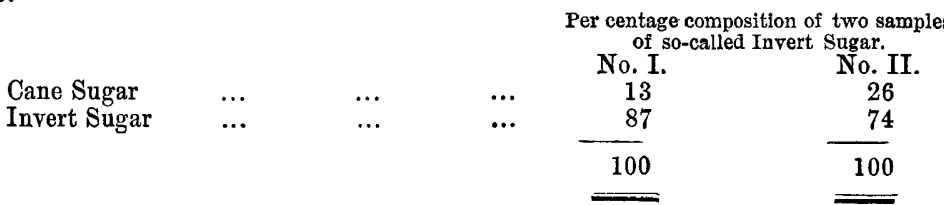

Their value as substitutes for malt can be easily estimated from what has been said above upon cane sugar, and from the fact that invert sugar only yields from 48 to 49 per cent. of alcohol, by fermentation.

The next set of bodies are the so-called "saccharines," or glucoses, \&c., produced by the action of sulphuric acid upon starch or starchy substances.

The following are analyses of five samples of saccharines from different makers :-

Sample No. 1.-Rather brown; very hard; English manufacture.

Sample No. 2.-Pale straw colour; softish; French manufacture.

Sample No. 3.-Rather white; somewhat hard; English manufacture.

Sample No. 4.-Rather white; somewhat hard; German manufacture.

Sample No. 5.-Whiter; somewhat hard; German manufacture.

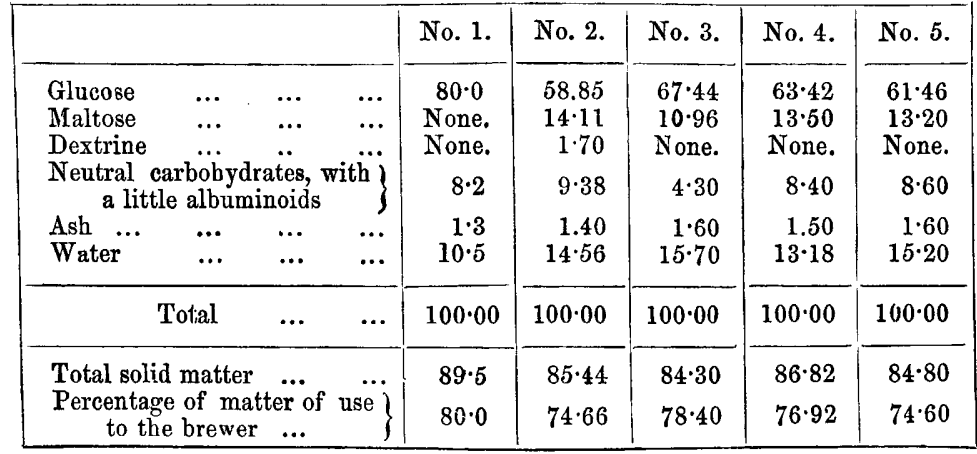


These analyses require little explanation, and very little comment of any kind.

The glucose is of the $\mathrm{C}^{6} \mathrm{H}^{12} \mathrm{O}^{6}$ type, and yields only 48 to 49 per cent. of alcohol, on fermentation.

The neutral carbohydrates are useless to the brewer, for although they increase the specific gravity of the beer, they are devoid of taste and "body-giving" properties. They, under no condition, yield alcohol, and cannot be converted like dextrine by the slow and gradual action of the beer into bodies capable of yielding this substance.

If the analyses of these saccharines be examined and compared with that of the maltwort, it will be seen that they have only one constituent in common, viz., maltose, and this exists in the saccharines in such small quantity as to be of little consequence.

A slight consideration of the composition and properties of dextrine-maltose will show at once its great superiority over all other malt substitutes offered to the brewer.

It contains in 100 parts in round numbers :-

$$
\begin{array}{llllll}
\text { Maltose } . . . & \ldots & \ldots & \ldots & \ldots & 67 \\
\text { Dextrine... } & \ldots & \ldots & \ldots & \ldots & \frac{33}{100 \cdot 0}
\end{array}
$$

Maltose yields the same proportional quantity of alcohol as cane sugar does, and the alcohol it yields is, in flavour, as far superior to the raw alcohol of the glucose of the saccharines, as that of fine malt whiskey is to potato spirit. In fact, the fine flavour of malt spirit is due to the fermentation of maltose, and that of the so-called potato spirit, to that of glucose. This is another reason why the saccharines have not come into more general use. There is far more yeast forming albuminoid matter in malt-wort than is required to ferment its saccharine constituents, and an addition of dextrine-maltose in varying proportions will have the additional effect of removing a further quantity of this yeast-forming matter from the beer before it goes into the casks.

In the manufacture of dextrine-maltose, when rice is employed it should be husked and finely ground. The rice-meal is first steeped in from 1 to $1 \frac{1}{2}$ times its weight of cold acidulated water, or in water not higher than $40^{\circ} \mathrm{C}$, and thoroughly agitated by mechanical means. It is then gradually introduced into acidulated boiling water, in the proportion of 100 parts by weight of rice to 250 by weight of the latter, care being taken not to allow the temperature to fall much below $90^{\circ} \mathrm{C}$. The amount of acid-by preference sulphuric-may vary. We employ from $1 \frac{1}{2}$ to 2 or 3 parts per cent. A dilute acid is preferable, for although the converting action is not quite so rapid, it proceeds much more regularly.

The vessel in which the rice-meal is converted consists of an ordinary mash tun, lined with sheet lead and provided with steam coils and a stirrer. As soon as the rice has become thoroughly diffused throughout the boiling water, a rapid conversion is observed. The liquid boils up briskly, and the steam has to be checked for a while to prevent its boiling over. This action is evidently owing to a chemical change. The rice-paste becomes rapidly thinner, when kept at a boiling temperature for about an hour or an hour and a-quarter. It is best and most expeditiously tes ed by neutralising a sample with baryta-water or chalk, filtering and examining the clear solution by means of the polariscope. 
The conversion may be considered complete when the rotatory power is $+171^{\circ}$ or thereabout, indicating two parts of maltose (rotatory power $+150^{\circ}$ ) and one part of dextrine (rotatory power $+213^{\circ}$ ), i.e.

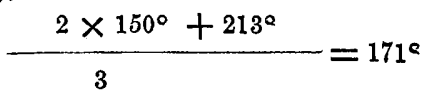

By always infusing the same quantities of rice-meal and keeping up the same temperature, it is possible, after a few experiments, to dispense with the polariscopic determination altogether, and to obtain a liquor containing the proportionate quantities of dextrine and maltose, as they are found in malt-wort. The acid liquor is then carefully neutralised with good chalk to the extent of about 90 per cent., finishing off with milk of lime. This operation can be carried out with the greatest delicacy. It is preferred to leave the liquor, however, rather a trifle acid than alkaline. The strength of the liquor, after filtering off the grains, and the gypsum through Taylor's filtering bags, usually amounts to 1,115 to 1,125 , or 30 to 32.5 per cent. of solid matter, i.e., about double the strength or original gravity of malt-wort required for brewing strong ales. It is of a light amber colour and filters very readily. It is next evaporated either in an open pan, or with greater advantage in a vacuum pan, to a concentration of about 1,200 , or about 52 per cent. of solid matter. A little more gypsum and a little flocculent albuminoid matter are at this stage best separated by filtration, and the concentrated liquor finished off in a properly constructed vacuum pan, or in an open steam-jacketed pan, provided with an agitator, till it acquires a stiff viscidity: It is then run off hot into forms, and cast into cakes of convenient weight, which on cooling, set hard, and are ready to be sent to the brewery. 78 to 80 per cent. of the starch in rice, in fact every particle, can be converted into dextrine-maltose.

The cost of manufacture is not more than $25 \mathrm{~s}$. to $30 \mathrm{~s}$. per ton.

R. H. H. 